\title{
Results of Operations for Ureteric Reflux*
}

\author{
JOHN E. S. SCOTT \\ From the Department of Surgery, Medical School, University of Newcastle upon Tyne
}

An increasing amount of evidence from animal experiments is now accumulating (Sunshine, 1964; Scott, 1964a, b), which suggests that ureteric reflux predisposes to pyelonephritis. There is, as yet, no proof that the same phenomenon occurs in man, though the available evidence points in that direction. This evidence is, however, indirect and inconclusive, and will not be confirmed until a properly controlled series of cases has been studied in which the results in an operated group, selected at random, are compared with an unoperated group treated concurrently. Retrospective studies are valueless.

We believe that an interval of at least 3 years should elapse between the start of treatment and the assessment of results, before an accurate judgement can be made on the response of urinary infection to the surgical treatment of reflux. This time interval is also necessary to allow adequate comparison of surgically and conservatively treated cases, and to evaluate the health and growth of the affected kidneys, the most important factor in the whole problem. Since our own cases have not all been studied for this length of time, this paper will report our results purely with regard to the surgical treatment of ureteric reflux and not with regard to the progress of recurrent urinary infection.

If vesico-ureteric reflux is a dangerous condition, it is as important to prevent it as it is to eliminate it. It is sometimes necessary, in patients who do not have reflux, to detach the ureter from the bladder in order adequately to deal with some other pathology. If the ureter is reattached to the bladder in a manner that permits reflux to occur, one disease is substituted for another. Occasions where this situation may arise are in simple megaureter when it is necessary to excise the lowermost segment of the ureter down to its orifice and then re-anastomose it to the bladder. It may also arise during the excision of a bladder diverticulum or the lower end of a duplex ureter. These structures may be so intimately

\footnotetext{
* A paper read at a meeting of the British Association of Paediatric Surgeons in Edinburgh, July 1965.
}

connected to the ureter to be retained, that this ureter must be detached from the bladder and then re-anastomosed. Such operations must also have anti-reflux potentialities.

All the children in our series were examined by cystograms 6 months after operation to determine whether reflux had been stopped or prevented, and this examination is repeated after an interval of 3 years to ascertain whether the situation has changed. In the succeeding Tables, the cases included as not followed up are those that have not had their first post-operative cystogram.

There were 77 children in this series with 110 affected ureters (Table I). 10 children were subjected to nephro-ureterectomy because, on intravenous pyelography, the kidney appeared grossly scarred and had only poor function. It is interesting that in $\mathbf{5}$ of these children, the affected kidney was the lower pole of a duplex, one of which required a bilateral operation. 5 ureters in 4 children were operated on twice.

Operations on 79 ureters in 48 children were done purely to eliminate reflux (Table II). Table III shows the results of the operations. The Bischoff

TABLE I

Uretero-cystostomy and Anti-reflux Operations

\begin{tabular}{|c|c|c|c|}
\hline & & Patients & Ureters \\
\hline $\begin{array}{ll}\text { Total treated surgically } \\
\text { Nephrectomy } & \ldots \\
\text { Re-operation } & \ldots \\
\text { No follow-up } & .\end{array}$ & $\begin{array}{ll}\because & \cdots \\
\therefore & \cdots \\
\therefore & \cdots\end{array}$ & $\begin{array}{r}77 \\
10 \\
4 \\
12\end{array}$ & $\begin{array}{c}110 \\
11^{\star} \\
19\end{array}$ \\
\hline
\end{tabular}

* 5 had lower pole heminephro-ureterectomy for reflux into this pole of duplex kidneys: 1 of these was bilateral.

TABLE II

Anti-reflux Operations

\begin{tabular}{|c|c|c|c|c|c|}
\hline & & & & Patients & Ureters \\
\hline $\begin{array}{l}\text { Total } \\
\text { Re-operation } \\
\text { No follow-up }\end{array}$ & $\begin{array}{l}\cdots \\
\cdots\end{array}$ & $\ddot{*}$ & $\begin{array}{l}\ldots \\
\ldots\end{array}$ & $\begin{array}{r}48 \\
4 \\
6\end{array}$ & $\begin{array}{r}79 \\
5 \\
9\end{array}$ \\
\hline
\end{tabular}


TABLE III

Uretero-cystostomy and Anti-reflux Operations

\begin{tabular}{|c|c|c|c|c|c|c|c|c|c|c|}
\hline & & & \multicolumn{8}{|c|}{ Type of Operation } \\
\hline & & & \multicolumn{2}{|c|}{ Bischoff } & \multicolumn{2}{|c|}{ Advancement } & \multicolumn{4}{|c|}{ Re-implant (follow up) } \\
\hline & & & Patients & Ureters & Patients & Ureters & Patients & Reflux & Ureters & Reflux \\
\hline $\begin{array}{l}\text { Total } \ldots \\
\text { Failed } \ldots\end{array}$ & 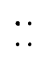 & $\begin{array}{l}\ldots \\
\cdots\end{array}$ & $\begin{array}{l}7 \\
5\end{array}$ & $\begin{array}{c}11 \\
7\end{array}$ & $\begin{array}{l}6 \\
1\end{array}$ & $\begin{array}{l}8 \\
1\end{array}$ & $\begin{array}{r}46 \\
0\end{array}$ & $\begin{array}{r}33 \\
0\end{array}$ & $\begin{array}{r}66 \\
0\end{array}$ & $\begin{array}{r}51 \\
0\end{array}$ \\
\hline
\end{tabular}

procedure was performed in 7 children, and since the results in our hands were disappointing, this method was abandoned. The advancement operation (Williams, Scott, and Turner-Warwick, 1961) proved to be reasonably successful, but was only done in 6 children. A total of 66 ureters in 46 children have been treated by the reimplantation technique; of these, 51 ureters in 33 children were operated purely to eliminate reflux. The operation did not fail to achieve its object in any of these cases. The method used was a modification of the one advocated by Paquin (1959) and McGovern and Marshall (1962), though the technique reported by Politano and Leadbetter (1958) was used bilaterally in one case with a satisfactory result. Table IV gives the details of those children who were reoperated, because the first operation had failed to

TABLE IV

Conversion Operations

\begin{tabular}{|c|c|c|c|}
\hline & Patients & Ureters & Failed \\
\hline $\begin{array}{l}\text { Bischoff } \rightarrow \text { Reimplant } \\
\text { Advancement } \rightarrow \text { Reimplant }\end{array}$ & $\begin{array}{l}3 \\
1\end{array}$ & $\begin{array}{l}4 \\
1\end{array}$ & $\begin{array}{l}0 \\
0\end{array}$ \\
\hline
\end{tabular}

eliminate reflux. The ureter was reimplanted in all cases and there were no failures. Table $\mathrm{V}$ shows the cases in which it was necessary to revise the uretero-vesical junction for lesions other than reflux, but in which, for reasons mentioned previously, it is important to avoid inducing reflux. The affected

\section{TABLE V}

Re-implant for Reasons other than Primary Anti-reflux Procedure, to Avoid Inducing Reflux

\begin{tabular}{|c|c|c|c|}
\hline Diagnosis & & Patients & Ureters \\
\hline $\begin{array}{l}\text { Diverticulum .. } \\
\text { Duplex kidney .. } \\
\text { Megaureter }\end{array}$ & $\begin{array}{l}\cdots \\
\cdots \\
\cdots \\
\cdots\end{array}$ & $\begin{array}{r}2 \\
3 \\
14 \\
6 \\
0 \\
0\end{array}$ & $\begin{array}{c}2 \\
3 \\
20 \\
\text { (4 with calculi) } \\
10 \\
0\end{array}$ \\
\hline
\end{tabular}

ureter was reimplanted into the bladder in each of these cases, and in none of those so far followed up was reflux induced.

Post-operative complications occurred in 2 cases, both of which had had the ureter from a solitary kidney reimplanted. Almost complete obstruction occurred at the anastomosis when the polythene catheter, which is used routinely to drain the ureter in the immediate post-operative period, was removed on the sixth post-operative day. Despite the fact that in both cases it was possible on cystoscopy to pass a ureteric catheter up the ureter without any difficulty and there was no apparent mechanical obstruction, the situation became so acute that pyelostomy was necessary. In both cases, 3 weeks after this was established, urine started draining from the ureter and it was possible to remove the pyelostomy tube; the wound closed rapidly. There were no further complications in either case, and their upper urinary tracts have not dilated.

One child died 7 months after operation. She had advanced renal failure with hypertension at the time of operation and, though the reflux was successfully treated, her renal failure progressed inexorably until death ensued. It is doubtful whether anything could have saved this child, though it is possible that some form of surface urinary diversion would have been more appropriate than the anti-reflux procedure.

Ureteric reflux can, therefore, be both prevented and eliminated by a surgical operation which, though requiring attention to certain details, is not difficult and is now well established. Though every surgeon adds his own modification to suit himself, the basic principles of creating a long intramural tunnel with usually a cuff on the termination of the ureter where it lies within the bladder, remain the same. This operation is followed by remarkably few complications and the long-term results from the mechanical point of view seem to be satisfactory. Whether this operation is the solution to the problem of recurrent urinary infection occurring in association with ureteric reflux has not yet been shown conclusively. We feel that a combination of operation and prolonged medical treatment will probably 
prove to be the answer, though there will always be a 'hard core' of cases that will defy all the methods of treatment presently available to us.

\section{REFERENCES}

McGovern, J. H., and Marshall, V. F. (1962). Reimplantation of ureters in children. Surg. Gynec. Obstet., 114, 143.

Paquin, A. J., Jr. (1959). Ureterovesical anastomosis: the description and evaluation of a technique. $\mathcal{F}$. Urol. (Baltimore), 82, 573.
Politano, V. A., and Leadbetter, W. F. (1958). An operative technique for the correction of vesicoureteral reflux. ibid., 79, 932.

Scott, J. E. S. (1964a). An experimental investigation into the effects of prolonged vesico-ureteric reflux. Brit. F. Urol., 36, 391.

(1964b). An experimental study of urinary infection and vesico-ureteric reflux. ibid., 36, 501.

Sunshine, H. (1964). The prevention of ascending pyelitis by the intact ureterovesical junction: an experimental study. F. Urol. (Baltimore), 92, 351.

Williams, D. I., Scott, J., and Turner-Warwick, R. T. (1961). Reflux and recurrent infection. Brit. $\mathcal{F}$. Urol., 33, 435. 